\title{
An Evidence Based Restoration of Esthetically Challenged Maxillary Anterior Arch with Andrews Bridge System - A Case Report with 5 Years of Follow Up
}

\section{Dhanasekar Balakrishnan ${ }^{1}$, Manawar Ahmad ${ }^{2 *}$, Abdullatif Albinali ${ }^{3}$, Ahmed Areashi $^{4}$ and Hina $\mathrm{Naim}^{2}$}

${ }^{1}$ Department of Prosthodontics, Manipal College of Dental Sciences, Manipal, India ${ }^{2}$ Department of Prosthodontics, College of Dentistry, Jazan University, Saudi Arabia

${ }^{3}$ Senior Resident, Restorative Dentistry, Saudi Board, Saudi Arabia

${ }^{4}$ Dental Intern, College of Dentistry, Jazan University, Saudi Arabi

\begin{abstract}
The replacement of missing teeth and restoration of alveolar contour has always presented a problem in those patients who have suffered traumatic injuries to the anterior dentition and alveolar processes. Many of these injuries lead to excessive loss of the residual ridge and make it extremely difficult to restore with a conventional fixed prosthesis. Due to constrain of fixed pontic in relation to these residual ridges, the use of this modality is virtually eliminated as a successful means of restoring such defects. An approach to the treatment in such patients has been conceived whereby a removable pontic section is supported directly by adjacent abutment teeth in a manner similar to that of fixed prosthesis. This case report represents restoration of esthetically compromised partially edentulous maxillary anterior arch with a fixed-removable prosthesis. This article also illustrates the indications, advantages, disadvantages and limitations of the Andrews bridge system.
\end{abstract}

Keywords: Andrew's bridge; Fixed restorations; Fixed-removable prosthesis

\section{Introduction}

The fixed-removable partial denture, also known as an Andrew's bridge has a pontic assembly that is removed by the patient for preventive maintenance [1]. Primary indications for this restoration are cases where the abutments are capable of supporting a fixed partial denture but the residual ridge has been partially lost due to trauma, congenital defects or other pathologic processes so that a conventional fixed partial denture would not adequately restore the patient's missing teeth and supporting structures [1-4].

The fixed-removable prosthesis consists of a substructure designed for the specific contour of the residual ridge being treated and it is attached with the abutment castings. The bar is specifically designed and fabricated to the contour of the residual ridge. A matching suprastructure to which the replacement teeth are attached is fabricated and fitted accurately to the substructure. It provides exceptional retention and resistance to rotational forces for the supra-structure. The position of substructure bar is determined largely by the position of the replacement teeth. It should be placed immediately lingual to these teeth so that excessive bulk in the lingual contour of the superstructure can be avoided or minimized. The substructure bar is developed in wax in the predetermined place in the edentulous ridge. The path of placement, although essentially vertical in direction, should allow the superstructure to be placed from the labial aspect towards the lingual to minimize the embrasures between the abutment teeth and replacement teeth [5-8].

\section{Case Report}

A 46 year old male patient reported with the chief complaints of missing anterior teeth in the upper jaw and his unaesthetic appearance. His past dental history revealed the loss of teeth due to trauma 4 years back. Intra oral examination showed loss of maxillary left and right central incisors (Figure 1). There was an adequate amount of alveolar bone loss in both vertical and horizontal direction at the maxillary anterior edentulous site, which was confirmed with intraoral radiographs (Figure 2). There were no clinically significant findings on the remaining maxillary teeth. The condition of abutment teeth was evaluated and the treatment plan was to fabricate the fixedremovable prosthesis to restore this esthetically challenged maxillary edentulous region. Another treatment option was implant placement after augmentation of the maxillary edentulous ridge however; this approach was not acceptable to the patient for financial reasons.

Intentional root canal therapy of the right and left maxillary lateral incisors was carried out (Figure 2). The abutment teeth were prepared for ceramo-metal preparations with more reduction on the axial walls of abutments approximating the pontic to allow space for joining the supra-structure bar and metal retainer. It reduces the chances of breakage of the bar and retainer at this junction. Double mix single

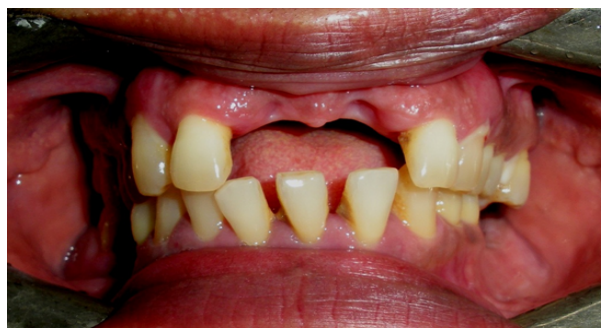

Figure 1: Pre-operative intra oral view.

*Corresponding author: Manawar Ahmad, Assistant Professor of Prosthodontics, College of Dentistry, Jazan University, Jazan, 114, Saudi Arabia, Tel: +96 6553662853; E-mail: ahmad955mls@gmail.com

Received December 11, 2015; Accepted January 09, 2016; Published January 16, 2016

Citation: Balakrishnan D, Ahmad M, Albinali A, Areashi A, Naim H (2016) An Evidence Based Restoration of Esthetically Challenged Maxillary Anterior Arch with Andrews Bridge System - A Case Report with 5 Years of Follow Up. Dentistry 6: 357. doi:10.4172/2161-1122.1000357

Copyright: $(2016$ Balakrishnan D, et al. This is an open-access article distributed under the terms of the Creative Commons Attribution License, which permits unrestricted use, distribution, and reproduction in any medium, provided the original author and source are credited. 


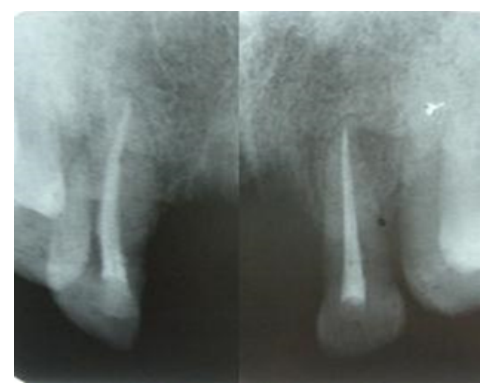

Figure 2: IOPA of maxillary anterior region showing bone loss.

step impression technique was used to make the final impression using light and medium body elastomeric impression material. Master casts were poured and mounted in the articulator. Inlay wax patterns for the retainers were made on the prepared dies. Supra-structure bar was made with inlay wax and attached to the wax pattern. The bar, which is positioned for the least restrictive path of insertion, should provide at least $1.5 \mathrm{~mm}$ of occlusal clearance and should be positioned in the same horizontal position as the center of the pontic teeth. The entire wax assembly was then cast. Finishing and polishing of the metal framework was done in the conventional manner. Metal frame work was inserted in the mouth to verify the proximal, marginal and occlusal relationships and the shade selection was done. Adequate space for the substructure to replace the missing teeth was verified. A $0.5 \mathrm{~mm}$ deep groove was made on the facial and palatal side of the super-structure. This groove helps in the retention of substructure. Wax pattern was fabricated over the super-structure and casted, finished and polished. The substructure was verified to check the fit over the super-structure. Self-cure acrylic base plate was adapted over the substructure and bite registration was done. Teeth arrangement was carried out and patient was called for try-in appointment. The porcelain was finally contoured and stained at this point before it is glazed. The flange was festooned and removable pontic was processed in heat cure acrylic (Figures 3 and 4). At the final insertion appointment, the restoration was adjusted before cementation. The framework was cemented first without the pontic on the bar to assure that the abutments were fully seated. The framework should not impinge on the tissue (Figure 5). The tissue surface of the bar was grounded and polished to relieve contact with the interdental papilla.

The patient was trained to properly place and remove the removable denture from the fixed component of Andrew's bridge. Proper oral hygiene instructions were given to the patient and recalled after 2 weeks to check the adaptability (Figure 6). Patient was completely satisfied. Home care instructions were given and recalled at regular intervals. After 5 years patient was evaluated to access the success of treatment which was well adapted to the Andrew's bridge system (Figure 7).

\section{Discussion}

Among the various restorative treatments developed for the patients with an unaesthetic edentulous space is the fixed removable partial denture. The Andrew's bridge system is usually of two types based on the area of bar attachments namely pontic supported and bone anchored or implant supported Andrew's bar system. In case of pontic supported Andrew's bridge system, the bar and sleeve provides retention which allows the pontic to seat on the ridge before the sleeve bottoms out on the bar preventing full bar seating. It also allows the pontic to be entirely ridge borne.
Compared to the conventional removable partial denture, the fixed-removable partial denture is more stable because it is totally tooth borne and the occlusal forces are directed more along the long axes of the abutment teeth. The location of bar near the gingival margin and decreased mobility of the splinted teeth support the two principles of physics in increasing the stability of the abutments. The framework is

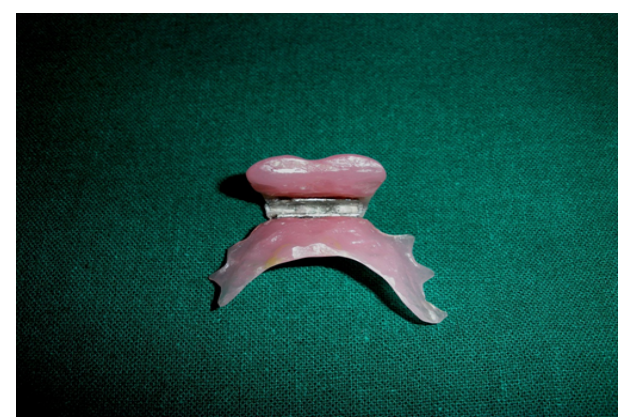

Figure 3: Superstructure attached to the removable prosthesis.

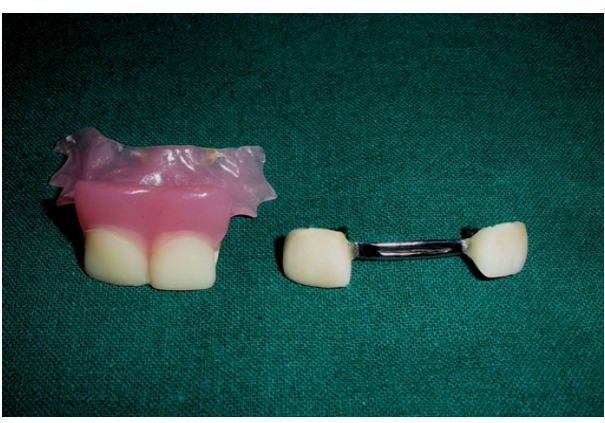

Figure 4: Fixed-removable prosthesis.

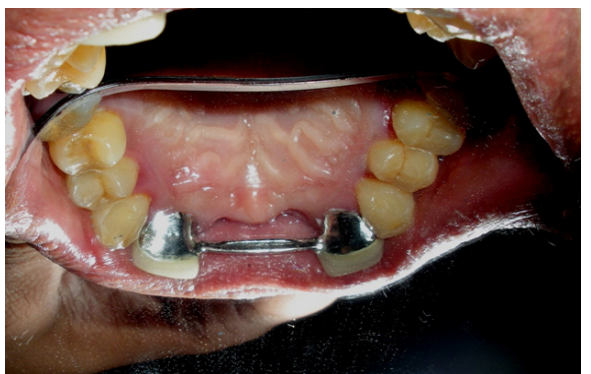

Figure 5: Palatal view after cementation.

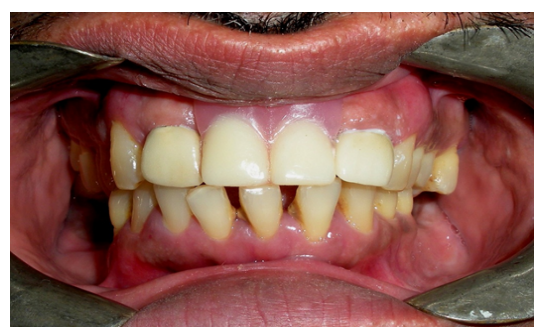

Figure 6: Intra-oral view of Andrews Bridge. 


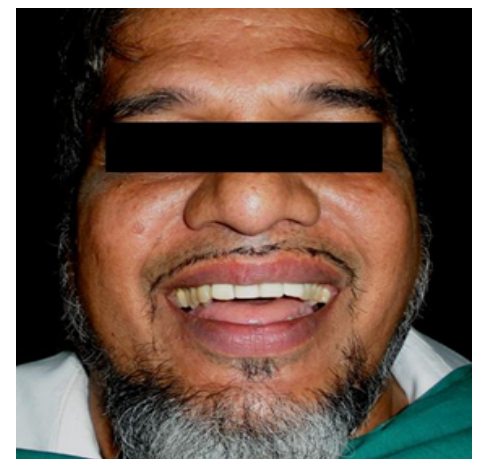

Figure 7: Extra oral view after 5 years.

constructed of ceramo-metal retainers which can be contoured and stained at the framework try-in appointment [9-11].

Compared to the conventional fixed partial denture, the pontic teeth are arranged during the esthetic try-in appointment. The flange of the pontic assembly is contoured to improve the comfort, esthetics and phonetics and to resist the possible torque during function. Moreover, the pontic assembly is removed to facilitate hygiene procedures and may be relined as the ridge resorbs. In this way a replacement or pontic section could be used that would cover a minimum of soft tissue; afford a means of replacement of teeth with optimum esthetic arrangement; compensates for soft tissue defects and could be removed by the patient for easy day-to-day hygiene [12-14]. The only failure in the bar is due to inadequate soldering, and this failure can be eliminated by casting the retainers directly to the bar. The wear and fracture incidence seen in pontic assemblies are similar to those found in conventional removable partial dentures and can be easily repaired. During this time, only a few adjustments with three-prong pliers are needed $[15,16]$.

\section{Conclusion}

The pontic supported Andrew's bridge system is particularly indicated for the patients with extensive supportive tissue loss and when alignment of opposing arch and esthetic arch position of the replacement teeth creates difficulties. The Andrew's bridge system provides maximum esthetics, maximum hygiene, optimum loading conditions and minimum trauma to the soft tissues. It is also very economical.

\section{References}

1. Everhart RJ, Cavazos E Jr (1983) Evaluation of a fixed removable partial denture: Andrews Bridge system. J Prosthet Dent 50: 180-184.

2. Rhoads JE (1982) The fixed-removable partial denture. J Prosthet Dent 48 : 122-129.

3. Tylman SD, Malone WFP (1978) Tylman's Theory and Practice of Fixed Prosthodontics. $\left(7^{\text {th }}\right.$ edn), Mosby, St. Louis.

4. Schillingburg HT, Hobo S, Whitsett LD (1978) Fundamentals of Fixed Prosthodontics. Quintessence Publishing Co, Chicago.

5. Seals RR Jr, Schwartz IS (1985) Successful integration of fixed and removable prosthodontics. J Prosthet Dent 53: 763-766.

6. Mueninghoff KA, Johnson MH (1982) Fixed-removable partial denture. $J$ Prosthet Dent 48: 547-550.

7. Shankar RY, Raju AV, Raju DS, Babu PJ, Kumar DR, et al. (2011) A fixed removable partial denture treatment for severe ridge defects. Int J Dent Case Rep 1: 112-118.

8. Immekus JE, Aramany M (1975) A fixed-removable partial denture for cleft palate patients. J Prosthet Dent 34: 286-291.

9. Walid MS (1995) Bone anchored Andrew's bar system a prosthetic alternative. Cairo Dent J 11: 11-15.

10. Tambe A, Patil SB, Bhat S, Badadare MM (2014) Andrew's bridge system an aesthetic and functional option for rehabilitation of compromised maxillary anterior dentition. BMJ Case Rep.

11. Bhapkar P, Botre A, Menon P, Gubrellay P (2015) Andrew's bridge system: an esthetic option. J Dent Allied Sci 4: 36-40.

12. Rao Y, Yadav P, D'Souza M, Singh J, Jain A (2013) Bar and sleeve attachment A report of two cases. J Clin Diagn Res 7: 3096-3098.

13. Muthuvignesh J, Bhuminanthan S, Egammai S, Donapati NR (2013) Improving facial esthetics with Andrew's bridge: a clinical report. Indian J Multidiscip Dent 4: 884-887.

14. Kaurani P, Samra RK, Kaurani M, Padiyar N (2013) Prosthodontic rehabilitation of a case with an anterior ridge defect using Andrew's bridge. Indian J Dent Sci 2: 100-103.

15. Cheatham JL, Newland JR, Radentz WH, O'Brien R (1984) The 'fixed' removable partial denture: report of case. J Am Dent Assoc 109: 57-59.

16. Carlson AF (1979) Introduction to the Andrews System of restorative dentistry Quintessence Dent Technol 3: 27-34. 